\title{
New Diagnostic Technique for Rapid Fluorescence Immunocytochemical Staining of Adenocarcinoma and Mesothelial Cells Using Liquid-Based Cytology
}

\author{
Ayumi Morimoto $^{a}$ Akihiro to $^{b}$ Katsunori Hashimoto ${ }^{c}$ Akinobu Nakano $^{a}$ \\ Tetsuro Nagasaka ${ }^{c}$ Toyoharu Yokoi ${ }^{d}$

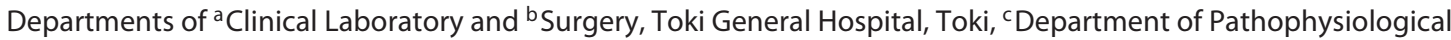 \\ Laboratory Sciences, Nagoya University Graduate School of Medicine, Nagoya, and d Department of Diagnostic \\ Pathology, Aichi Medical University Hospital, Nagakute, Japan
}

\section{Key Words}

Adenocarcinoma $\cdot$ Mesothelial cell $\cdot$ Fluorescence

immunocytochemistry - Liquid-based cytology

\begin{abstract}
Objective: To evaluate the expression of antibodies against calretinin, cytokeratin 5/6, desmin, D2-40, HBME-1, mesothelin, thrombomodulin, WT1, Ber-EP4, CEA, EMA and MOC31 individually and to compare it with a new rapid procedure for fluorescence immunocytochemistry (ICC) using liquidbased cytology (LBC). Study Design: Sixty-four peritoneal cell specimens prepared with the LBC method were stained with these markers to evaluate their usefulness and develop a rapid fluorescence immunostaining method using Ber-EP4 that is applicable to intraoperative cancer cytodiagnosis. $\boldsymbol{R e}$ sults: The adenocarcinoma markers were positive in $92 \%$ of adenocarcinoma cases, $57 \%$ of cases with suspicion of adenocarcinoma, and $5 \%$ of negative cases (reactive mesothelial cells). On the other hand, the mesothelial cell markers were positive in $8-15 \%$ of adenocarcinoma cases, $43-57 \%$ of cases with suspicion of adenocarcinoma, and $93-95 \%$ of negative cases. The rapid new fluorescence ICC procedure clearly stained only the adenocarcinoma cells within $20 \mathrm{~min}$.
\end{abstract}

Conclusion: Immunocytochemical examination with the LBC method is a powerful ancillary technique for discriminating adenocarcinoma cells from mesothelial cells. This rapid new fluorescence ICC procedure can be used as an ancillary technique for accurate detection of adenocarcinoma cells in the intraoperative cytological examination of peritoneal or pleural washing fluid.

(c) 2014 S. Karger AG, Basel

\section{Introduction}

Cytological diagnosis of malignant effusions is often difficult mainly because of the presence of reactive mesothelial cells. Differentiation of malignant cells, especially adenocarcinoma cells, from reactive mesothelial cells has been the most common and serious diagnostic difficulty in effusion cytology [1-3]. In addition to the conventional body fluid cytology, intraoperative cytological examination of peritoneal or pleural washing fluids has recently been introduced for rapid assessment of the clinical stage of the patient. Intraoperative cytological examination of peritoneal washing fluid is now listed as one of the prognostic factors and its performance is recommended

\section{KARGER}

E-Mail karger@karger.com

www.karger.com/acy
(C) 2014 S. Karger AG, Basel

0001-5547/14/0585-0461\$39.50/0
Correspondence to: Dr. Ayumi Morimoto

Department of Clinical Laboratory

Toki General Hospital

703-24 Tokiguchi, Tokitsucho, Toki, Gifu 509-5193 (Japan)

E-Mail a.morimoto@mbr.nifty.com 
according to the Japanese Classification of Gastric Carcinoma [4]. Adenocarcinoma cells in the peritoneal washing fluid are considered an important factor for peritoneal dissemination when making a prognosis. This information is considered crucial for surgeons so as to perform operations according to the most reliable detection techniques.

Immunocytochemistry (ICC) has been applied to aid the differentiation of adenocarcinoma and reactive mesothelial cells $[1,2,5]$, but is not very useful largely because of the limited number of specimens, in contrast to immunohistochemistry, in which a sufficient number of consecutive sections are available for each tissue specimen. Liquid-based cytology (LBC) systems have been widely applied not only to gynecological cytology but also to nongynecological cytology [6-8]. LBC is superior to conventional cytology in that it provides smear slides with a uniform cell density and a distribution that enables a precise cytological examination. Moreover, one can preserve cells in the LBC solution for a long period of time and always utilize it for a variety of purposes, such as ICC and molecular analysis.

Over the years, many different markers have been tried to elucidate difficult cases. Based on these experiences and more recent literature findings, a test panel of 13 antibodies was selected, which was supposed to be capable of differentiating between adenocarcinoma cells and reactive mesothelial cells. The immunocytochemical markers Ber-EP4, CEA, EMA and MOC-31 have been reported to be highly expressed in adenocarcinomas or epithelial tumors in general and not in reactive mesothelial cells. The other markers, calretinin (mouse monoclonal and rabbit monoclonal antibody), cytokeratin 5/6, desmin, D2-40, HBME-1, mesothelin, thrombomodulin and WT1, are thought to be those of mesothelial cells, although their specificities vary depending on the marker.

In the present study, we performed immunocytochemical analysis on 64 peritoneal cell specimens prepared with the LBC method to evaluate its usefulness, and we developed a new and rapid procedure for fluorescence immunostaining that is applicable to intraoperative cancer cytodiagnosis.

\section{Materials and Methods}

\section{Clinical Materials}

Sixty-four peritoneal cell specimens, 35 intraoperative peritoneal washing fluids and 29 peritoneal effusions, were studied at the Department of Pathology, Toki General Hospital, from 2008 to 2010 (table 1). Patients were 38 men and 26 women aged 35-88 years (mean 68.6). Peritoneal cell specimens were centrifuged and an aliquot of the cell pellet was prepared for conventional Papanicolaou, periodic acid-Schiff (PAS) and Giemsa stains, then fixed in 95\% ethanol more than $15 \mathrm{~min}$ and processed for routine cytomorphologic evaluation (table 1). After sampling the routine materials, the rest of the cell pellet was suspended in the LBC solution (LiquiPREPTM Preservative Solution, LGM International Inc.) for fixation and preservation.

Preparation of LBC Slides for Papanicolaou Stain and ICC

An aliquot of cells preserved in LBC solution was centrifuged and the cell pellet was suspended in Cellular Base Solution (LiquiPREP, LGM International), dropped on the glass slide and dried at room temperature when used for Papanicolaou stain and ICC. After microwave heat treatment for $15 \mathrm{~min}(5 \mathrm{~min} / 3$ times $)$ in 10 $\mathrm{mmol} / \mathrm{l}$ citrate buffer $(\mathrm{pH} 6.0)$, the cell specimens were cooled at room temperature. Next, the cell specimens were treated with $0.3 \%$ hydrogen peroxide in methanol for $20 \mathrm{~min}$ at room temperature to block endogenous peroxidase activity, and the nonspecific reaction was blocked by treating with $10 \%$ normal goat serum (Nichirei, Tokyo, Japan) for $20 \mathrm{~min}$ at room temperature. Then, cell specimens were incubated with the primary antibodies listed in table 2 overnight at $4^{\circ} \mathrm{C}$. Subsequently, the specimens were reacted with Histofine reagent (Nichirei) for $30 \mathrm{~min}$ at room temperature and were visualized by DAB chromogen (Vector Laboratories, Inc.) for 15-360 s at room temperature. Finally, the cell specimens were immersed in distilled water to stop the reaction and were counterstained with Mayer's hematoxylin (fig. 1). Immunocytochemical expressions of the markers were evaluated according to the proportion of positive cells as follows: $-=$ no staining, $\pm=$ $<10 \%,+=10-50 \%,++=>50 \%$ independent of the results of the conventional cytomorphologic evaluation.

\section{Rapid Procedure for Fluorescence ICC}

This new procedure was performed on cells preserved in LBC solution using the liquid-phase method to save time. An aliquot of preserved cell solution was incubated with the primary antibody Ber-EP4 (1\%) and centrifuged for $5 \mathrm{~min}$ at room temperature concurrently. In this step, the antigen-antibody reaction is thought to fully develop during centrifugation. Then, the cell pellet was mixed with the $1 \%$ fluorescein anti-mouse IgG (Vector Laboratories) in PBS and centrifuged for $5 \mathrm{~min}$ at room temperature during which a secondary antigen-antibody reaction develops likewise. Subsequently, the cell pellet was suspended in Cellular Base Solution, dropped on the glass slide and dried with a dryer, and mounted with fluorescence mounting medium containing a blue counterstain (Vectashield ${ }^{\circledR}$ Mounting Medium with DAPI, Vector Laboratories). The specimen was observed with a fluorescence microscope (Olympus Provis AX80 + DP-70; fig. 2). The cytoplasm of positive cells was stained green by FITC (fig. 3).

\section{Standard Fluorescence ICC}

To compare the sensitivity and specificity, we performed the standard fluorescence ICC on cytology slides prepared from cells preserved in LBC solution. After $10 \%$ normal goat serum treatment for $20 \mathrm{~min}$ at room temperature, the cell specimens were incubated with the primary antibody Ber-EP4 for $1 \mathrm{~h}$ at room temperature. Then, the cell specimens were incubated with the $1 \%$ fluorescein anti-mouse IgG in PBS for $1 \mathrm{~h}$ at room temperature. Subsequently, the cell specimens were mounted with fluorescence 
Table 1. Clinical and cytomorphologic evaluation of 64 peritoneal cell specimens

\begin{tabular}{|c|c|c|c|c|c|c|}
\hline Patient & Age & Sex & Specimen & $\begin{array}{l}\text { Preliminary diagnosis } \\
\text { with Papanicolaou stain }\end{array}$ & Final diagnosis & Primary disease \\
\hline 1 & 45 & $\mathrm{~F}$ & $\mathrm{~W}$ & \multirow{13}{*}{ adenocarcinoma } & \multirow{12}{*}{ adenocarcinoma } & \multirow{6}{*}{ gastric cancer } \\
\hline 2 & 57 & $\mathrm{~F}$ & $\mathrm{E}$ & & & \\
\hline 3 & 74 & M & $\mathrm{W}$ & & & \\
\hline 4 & 73 & $\mathrm{~F}$ & $\mathrm{E}$ & & & \\
\hline 5 & 74 & $\mathrm{~F}$ & E & & & \\
\hline 6 & 46 & $\mathrm{~F}$ & $\mathrm{~W}$ & & & \\
\hline 7 & 67 & $\mathrm{~F}$ & $\mathrm{E}$ & & & \multirow{2}{*}{ pancreatic cancer } \\
\hline 8 & 54 & M & $\mathrm{E}$ & & & \\
\hline 9 & 65 & $\mathrm{M}$ & $\mathrm{W}$ & & & \multirow{3}{*}{ colorectal cancer } \\
\hline 10 & 77 & $\mathrm{M}$ & $\mathrm{W}$ & & & \\
\hline 11 & 74 & M & $\mathrm{W}$ & & & \\
\hline 12 & 88 & $\mathrm{~F}$ & $\mathrm{E}$ & & & unknown \\
\hline 13 & 80 & M & W & & mesothelial cell & gastric cancer \\
\hline 14 & 70 & $\mathrm{~F}$ & E & \multirow{7}{*}{ suspicious adenocarcinoma } & \multirow{4}{*}{ adenocarcinoma } & \multirow{3}{*}{ gastric cancer } \\
\hline 15 & 75 & $\mathrm{~F}$ & E & & & \\
\hline 16 & 72 & $\mathrm{~F}$ & $\mathrm{~W}$ & & & \\
\hline 17 & 69 & M & $\mathrm{W}$ & & & colorectal cancer \\
\hline 18 & 75 & $\mathrm{~F}$ & $\mathrm{E}$ & & \multirow{3}{*}{ mesothelial cell } & \multirow{2}{*}{ gastric cancer } \\
\hline 19 & 71 & $\mathrm{~F}$ & $\mathrm{~W}$ & & & \\
\hline 20 & 73 & M & $\mathrm{W}$ & & & colorectal cancer \\
\hline 21 & 70 & $\mathrm{~F}$ & E & \multirow{24}{*}{ mesothelial cell } & & gastric cancer \\
\hline 22 & 82 & M & $\mathrm{E}$ & & adenocarcinoma & cholangiocarcinoma \\
\hline 23 & 56 & M & $\mathrm{W}$ & & \multirow{22}{*}{ mesothelial cell } & \multirow{5}{*}{ gastric cancer } \\
\hline 24 & 75 & $\mathrm{M}$ & $\mathrm{W}$ & & & \\
\hline 25 & 35 & M & $\mathrm{W}$ & & & \\
\hline 26 & 72 & M & $\mathrm{W}$ & & & \\
\hline 27 & 76 & $\mathrm{~F}$ & $\mathrm{~W}$ & & & \\
\hline 28 & 75 & M & $\mathrm{E}$ & & & pancreatic cancer \\
\hline 29 & 75 & $\mathrm{~F}$ & $\mathrm{E}$ & & & cholangiocarcinoma \\
\hline 30 & 58 & $\mathrm{~F}$ & $\mathrm{~W}$ & & & endometrial cancer \\
\hline $31-51$ & $52-87$ & $\mathrm{M} 17, \mathrm{~F} 4$ & $\mathrm{~W} 17, \mathrm{E} 4$ & & & colorectal cancer \\
\hline 52 & 70 & $\mathrm{~F}$ & $\mathrm{E}$ & & & \multirow{4}{*}{ liver cirrhosis } \\
\hline 53 & 45 & $\mathrm{M}$ & E & & & \\
\hline 54 & 56 & M & $\mathrm{E}$ & & & \\
\hline 55 & 53 & M & $\mathrm{E}$ & & & \\
\hline 56 & 52 & $\mathrm{~F}$ & $\mathrm{~W}$ & & & Ileus \\
\hline 57 & 69 & M & E & & & \multirow{2}{*}{ Malignant lymphoma } \\
\hline 58 & 60 & M & $\mathrm{E}$ & & & \\
\hline 59 & 59 & $\mathrm{~F}$ & E & & & \multirow{3}{*}{$\begin{array}{l}\text { Renal failure } \\
\text { Nephrotic syndrome } \\
\text { COPD }\end{array}$} \\
\hline 60 & 57 & $\mathrm{~F}$ & $\mathrm{E}$ & & & \\
\hline 61 & 80 & $\mathrm{M}$ & E & & & \\
\hline 62 & 72 & $\mathrm{~F}$ & E & & & \multirow{3}{*}{ Unknown } \\
\hline 63 & 40 & $\mathrm{~F}$ & E & & & \\
\hline 64 & 75 & $\mathrm{M}$ & E & & & \\
\hline
\end{tabular}

$\mathrm{W}=$ Intraoperative peritoneal washing fluid; $\mathrm{E}$ = peritoneal effusion. 
Fig. 1. Typical microscopic appearance of immunocytochemical staining of LBC slides from patient 14. Adenocarcinoma cells were positive for Ber-EP4 (a), MOC31 (b), and EMA (c), but negative for calretinin mouse monoclonal antibody $(\mathbf{d})$. $\times 1,000$.
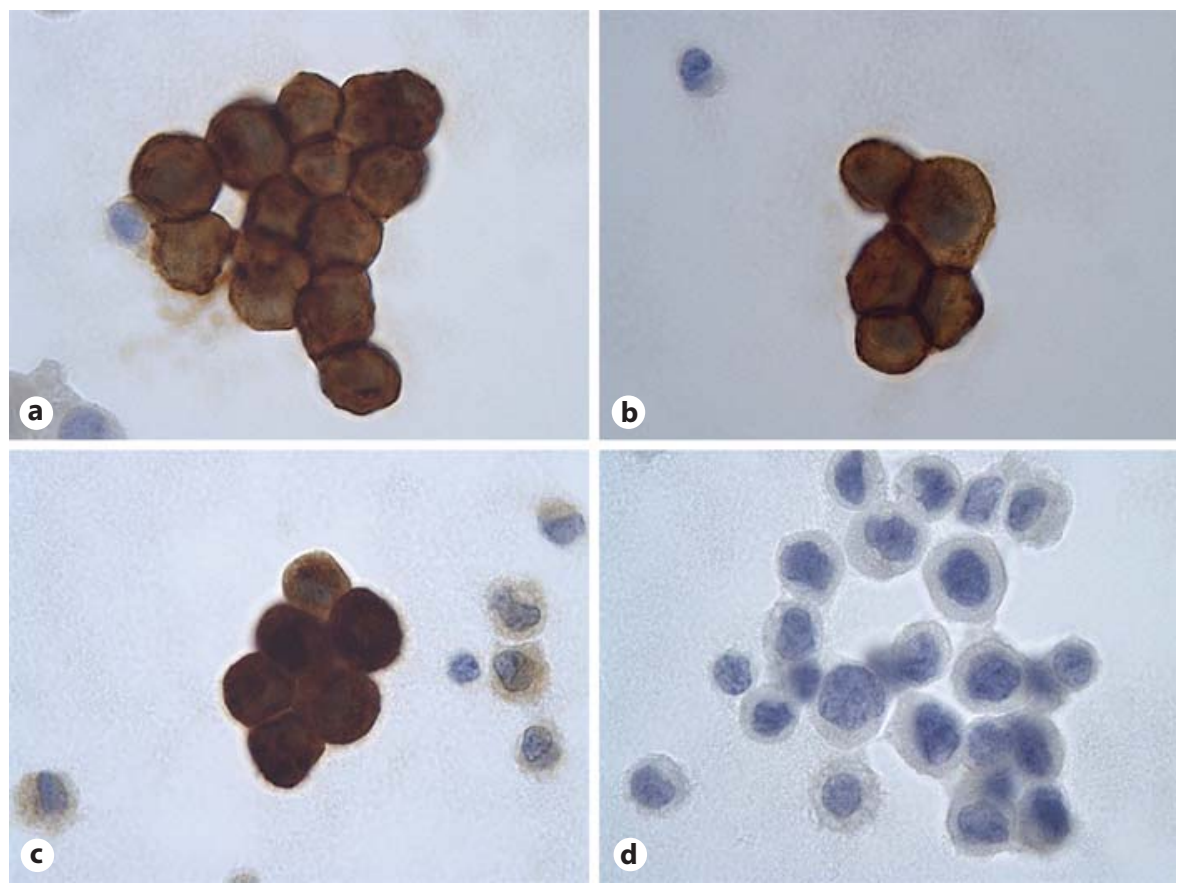

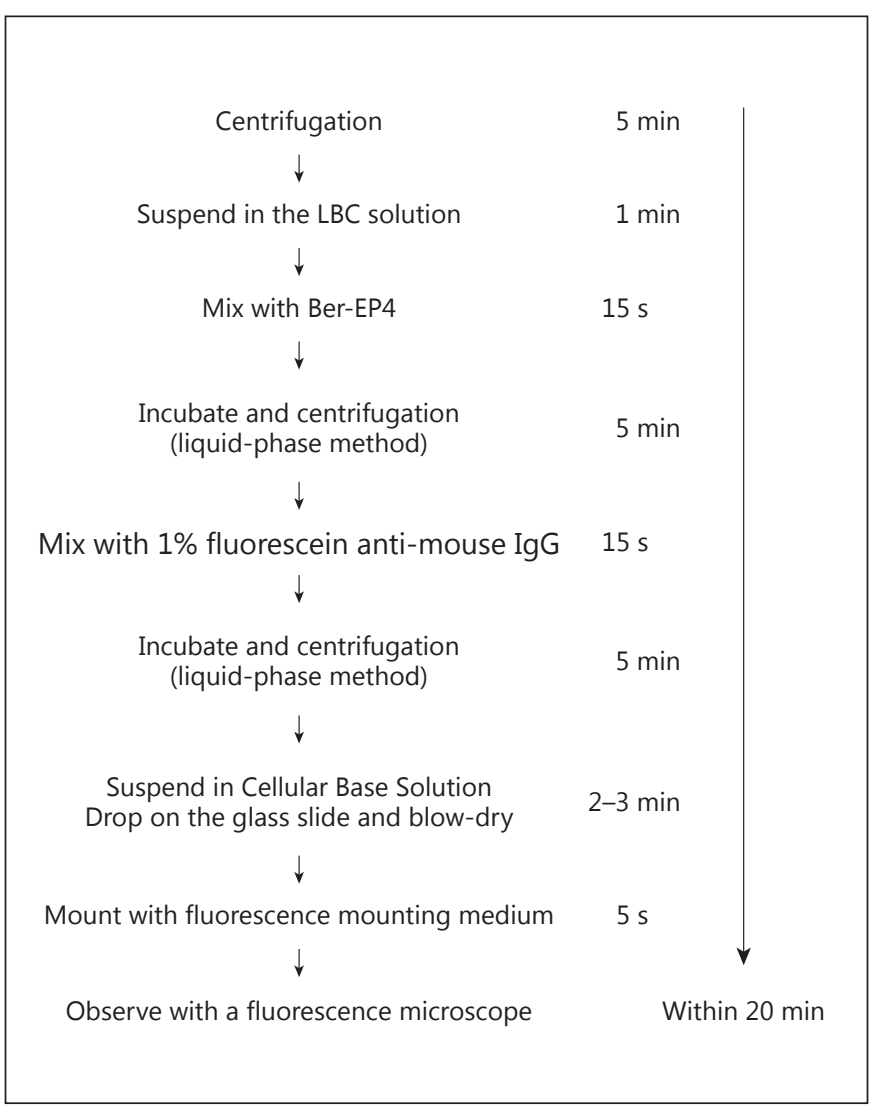

Fig. 2. Rapid procedure for fluorescence immunocytochemical staining. mounting medium containing a blue counterstain and observed with a fluorescence microscope the same as used for the rapid procedure for fluorescence ICC.

\section{Results}

\section{Cytological Features of LBC Slides}

There was no staining quality problem compared to slides stained using the conventional Papanicolaou stain. Cytomorphologic evaluation of the LBC specimens showed adenocarcinoma in 13, suspicion of adenocarcinoma in 7 , and negative (reactive mesothelial cell) in 44 , the same as the results of the conventional method (table 1).

\section{Standard ICC}

The results of the immunocytochemical examination are shown in table 3 . The adenocarcinoma markers BerEP4, CEA, EMA and MOC-31 were positive in 12 (92\%) of 13 adenocarcinoma cases, 4 (57\%) of 7 cases with suspicion of adenocarcinoma, and 2 (5\%) of 44 negative cases (reactive mesothelial cells). On the other hand, the mesothelial cell markers calretinin mouse monoclonal antibody, calretinin rabbit monoclonal antibody, cytokeratin 5/6, desmin, D2-40, HBME-1, mesothelin thrombomodulin and WT1 were positive in 1-2 (8-15\%) of 13 adenocarcinoma cases, 3-4 (43-57\%) of 7 suspicious adenocarcinoma cases, and 41-42 (93-95\%) of 44 negative cases 

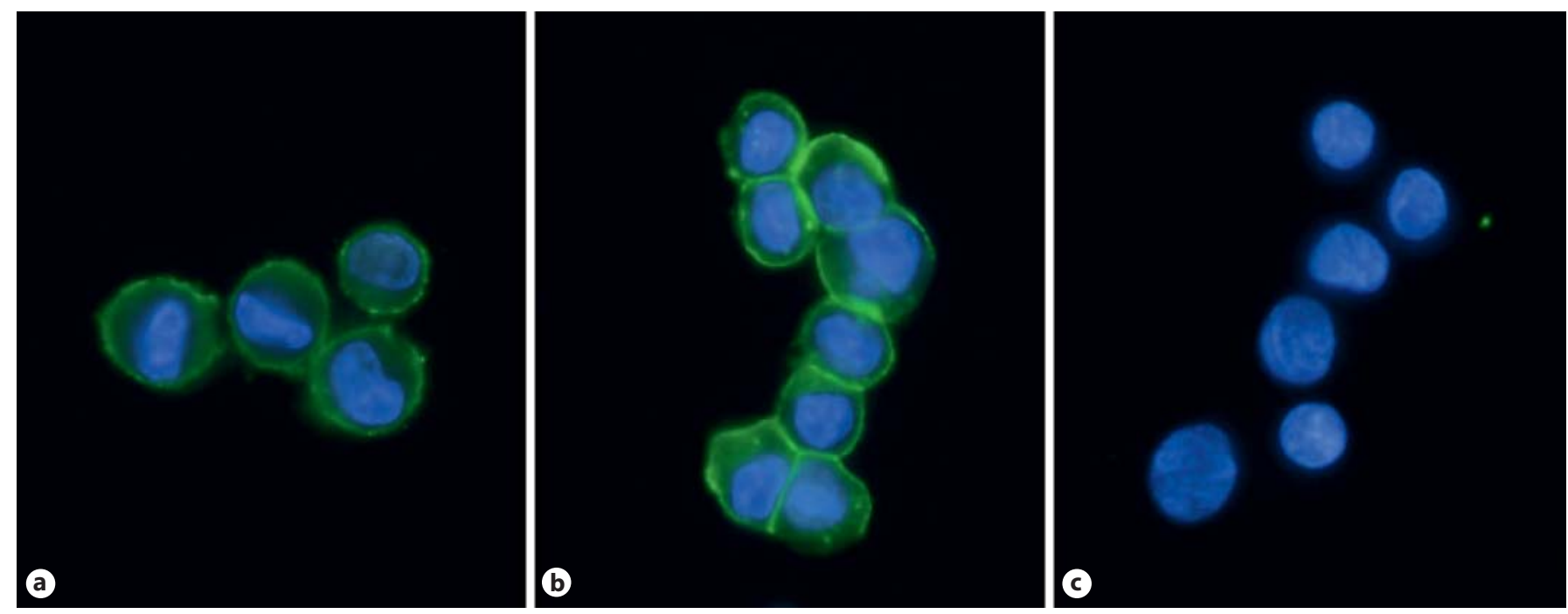

Fig. 3. Rapid procedure for fluorescence immunocytochemical staining. Adenocarcinoma cells were positive for Ber-EP4 (a, b), and mesothelial cells were negative (c). a Patient 2. b Patient 14. c Patient 28. $\times 1,000$.

Table 2. List of antibodies used

\begin{tabular}{|c|c|c|c|c|c|}
\hline Ber-EP4 & M (mouse) & Ber-EP4 & $1: 100$ & microwave, citrate buffer, pH 6.0 & Dako \\
\hline EMA & $\mathrm{M}$ (mouse) & E29 & $1: 100$ & none & Dako \\
\hline MOC-31 & M (mouse) & MOC-31 & $1: 60$ & microwave, citrate buffer, pH 6.0 & Dako \\
\hline Calretinin & M (mouse) & DAK Calret 1 & $1: 50$ & microwave, citrate buffer, pH 6.0 & Dako \\
\hline Desmin & M (mouse) & D33 & $1: 100$ & microwave, citrate buffer, $\mathrm{pH} 6.0$ & Dako \\
\hline D2-40 & M (mouse) & $\mathrm{D} 2-40$ & $1: 50$ & microwave, citrate buffer, pH 6.0 & Dako \\
\hline HBME-1 & $\mathrm{M}$ (mouse) & HBME-1 & $1: 50$ & none & Dako \\
\hline Mesothelin & $\mathrm{M}$ (mouse) & $5 \mathrm{~B} 2$ & $1: 20$ & microwave, citrate buffer, pH 6.0 & Novocastra \\
\hline Thrombomodulin & M (mouse) & 1009 & $1: 50$ & microwave, citrate buffer, pH 6.0 & Dako \\
\hline WT1 & $\mathrm{M}$ (mouse) & $6 \mathrm{~F}-\mathrm{H} 2$ & $1: 100$ & microwave, citrate buffer, pH 6.0 & Dako \\
\hline
\end{tabular}

$\mathrm{M}=$ Monoclonal; $\mathrm{P}=$ polyclonal.

(reactive mesothelial cells). With the ICC using LBC specimens, it was apparent that 18 cases were positive for adenocarcinoma cells and 46 cases were negative from all 64 cases. Moreover, it proved that a small amount of adenocarcinoma cells was intermingled in 2 of the 44 negative cases. In conclusion, in these 64 cases, using solely cytomorphologic evaluation with Papanicolaou stain, the sensitivity for the detection of adenocarcinoma was $89 \%$ (16 of 18), specificity was $91 \%$ (42 of 46) and diagnostic accuracy was $91 \%$ (58 of 64 ).

Rapid Immunocytodiagnosis Using LBC

\section{Rapid Procedure for Fluorescence ICC}

To quickly distinguish adenocarcinoma cells from mesothelial cells, the rapid fluorescence ICC procedure was performed on LBC samples. On the basis of the immunocytochemical results described above, Ber-EP4 was selected as an adenocarcinoma marker because it stained the most clearly without any nonspecific reaction. As shown in figure 4, adenocarcinoma cells were readily separated by fluorescence coloration with the antibody for Ber-EP4. Results of the rapid procedure for fluorescence ICC were 
Fig. 4. Typical microscopic appearance of conventional Papanicolaou-stained smear slide (a) and rapid procedure for fluorescence immunocytochemical staining of LBC slides (b) from patient 14. Adenocarcinoma cells were positive for Ber-EP4 (b). $\times 400$.
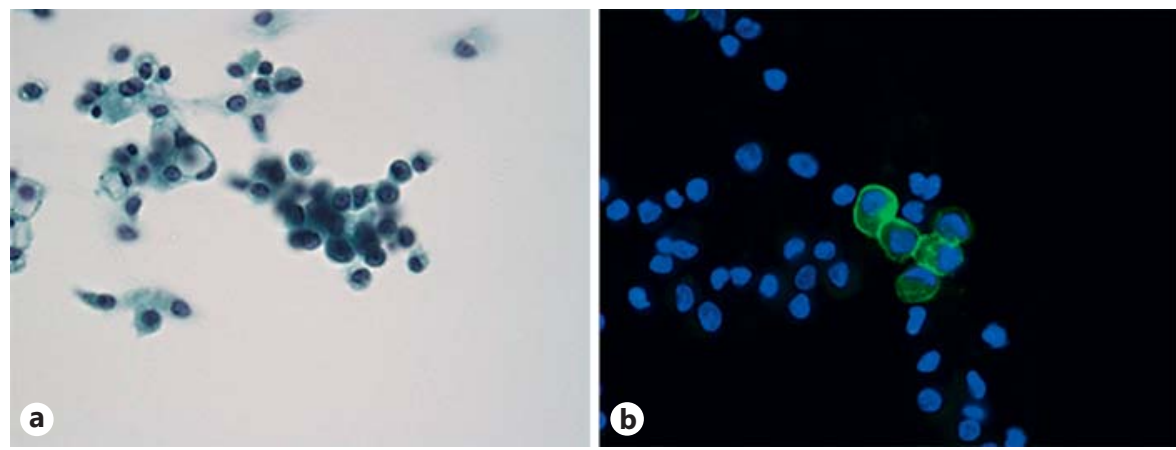

Table 3. Results of immunocytochemical expression of various markers

\begin{tabular}{|c|c|c|c|c|c|c|c|c|c|c|c|}
\hline $\begin{array}{l}\text { Preliminary diagnosis } \\
\text { with Papanicolaou stain }\end{array}$ & $\begin{array}{l}\text { Expres- } \\
\text { sion }\end{array}$ & $\begin{array}{l}\text { Ber-EP4 } \\
\text { MOC-31 }\end{array}$ & $\begin{array}{l}\text { CEA } \\
\text { EMA }\end{array}$ & $\begin{array}{l}\text { Calret } \\
(\mathrm{M})\end{array}$ & $\begin{array}{l}\text { Calret } \\
(\mathrm{R})\end{array}$ & CK5/6 & $\begin{array}{l}\text { Desmin } \\
\text { HBME-1 }\end{array}$ & D2-40 & Meso & $\mathrm{TM}$ & WT1 \\
\hline \multirow[t]{4}{*}{$\mathrm{AC}(\mathrm{n}=13)$} & - & 1 & 1 & 12 & 12 & 11 & 12 & 12 & 11 & 11 & 12 \\
\hline & \pm & 0 & 0 & 0 & 0 & 0 & 0 & 0 & 1 & 1 & 0 \\
\hline & + & 0 & 1 & 1 & 0 & 1 & 0 & 0 & 0 & 0 & 0 \\
\hline & ++ & 12 & 11 & 0 & 1 & 1 & 1 & 1 & 1 & 1 & 1 \\
\hline \multirow[t]{4}{*}{ Suspicious AC $(\mathrm{n}=7)$} & - & 3 & 3 & 4 & 3 & 4 & 4 & 4 & 4 & 3 & 4 \\
\hline & \pm & 0 & 0 & 0 & 0 & 0 & 0 & 0 & 0 & 1 & 0 \\
\hline & + & 0 & 0 & 1 & 2 & 0 & 0 & 1 & 1 & 1 & 0 \\
\hline & ++ & 4 & 4 & 2 & 2 & 3 & 3 & 2 & 2 & 2 & 3 \\
\hline \multirow[t]{4}{*}{ Mesothelial cell $(n=44)$} & - & 42 & 42 & 2 & 2 & 2 & 2 & 2 & 2 & 2 & 2 \\
\hline & \pm & 0 & 0 & 0 & 0 & 0 & 0 & 0 & 1 & 0 & 0 \\
\hline & + & 0 & 0 & 10 & 4 & 7 & 0 & 2 & 8 & 3 & 1 \\
\hline & ++ & 2 & 2 & 32 & 38 & 35 & 42 & 40 & 33 & 39 & 41 \\
\hline
\end{tabular}

$\mathrm{AC}=$ Adenocarcinoma; Calret $(\mathrm{M})=$ calretinin mouse monoclonal antibody; Calret $(\mathrm{R})=$ calretinin rabbit monoclonal antibody; CK5/6 = cytokeratin 5/6; Meso = mesothelin; $\mathrm{TM}=$ thrombomodulin; $-=$ no staining; $\pm=<10 \% ;+=10-50 \% ;++=>50 \%$.

Table 4. Comparison of three immunocytochemical methods

\begin{tabular}{llrrr}
\hline $\begin{array}{l}\text { Preliminary diagnosis } \\
\text { with Papanicolaou stain }\end{array}$ & Expression & ICC & FICC & RFICC \\
\hline \multirow{2}{*}{ AC $(\mathrm{n}=13)$} & - & 1 & 1 & 1 \\
& \pm & 0 & 0 & 0 \\
& + & 0 & 0 & 0 \\
& ++ & 12 & 12 & 12 \\
Suspicious AC $(\mathrm{n}=7)$ & - & 3 & 3 & 3 \\
& \pm & 0 & 0 & 0 \\
& + & 0 & 0 & 0 \\
Mesothelial cell $(\mathrm{n}=44)$ & - & 4 & 4 & 4 \\
& ++ & 42 & 42 & 42 \\
& + & 0 & 0 & 0 \\
& ++ & 0 & 0 & 0 \\
& + & 2 & 2 & 2 \\
\hline
\end{tabular}

$\mathrm{AC}=$ Adenocarcinoma FICC $=$ standard fluorescence immunocytochemistry; RFICC = rapid procedure for fluorescence immunocytochemistry; - = no staining; $\pm=<10 \%$; + = $10-50 \%$; $++=>50 \%$. the same as those of the standard fluorescence ICC (table 4). Using the rapid procedure for fluorescence ICC, we could clearly stain only the adenocarcinoma cells within $20 \mathrm{~min}$ in 18 of the adenocarcinoma cases.

\section{Discussion}

A wide variety of immunocytochemical markers have been applied to distinguish adenocarcinoma cells from reactive mesothelial cells or malignant mesothelioma in body fluid effusion cytology or serosal histology $[9,10]$. CEA is probably the most popular marker for adenocarcinoma and has been widely used because of its high specificity [9]. In this study, adenocarcinoma cells showed strong expression of CEA, as shown in previous reports, reconfirming that this is an excellent marker for adenocarcinoma. However, the presence of a nonspecific reaction to leukocytes often makes precise evaluation diffi- 
cult. This is why other markers have been sought as more specific markers for adenocarcinoma. The expression of EMA is seen in epithelial tumors in general and also in some nonepithelial tumors. This marker is known to be expressed in malignant mesothelioma cells, by its strong, predominantly membranous staining pattern; however, when its presence in a predominantly cytoplasmic staining pattern is indicative of an adenocarcinoma, it is used in the crucial differential diagnosis of malignant mesothelioma cells and adenocarcinoma cells [11]. Despite an expression in a fairly wide spectrum of tumors and nontumorous cells, EMA is still useful for distinguishing adenocarcinoma cells from mesothelial cells in effusions, as shown in this study and in previous reports. MOC-31 and Ber-EP4 are rather new markers introduced into the field of diagnostic pathology and cytology practice $[1,9,12$, 13]. MOC-31 is reported to be fairly specific for adenocarcinoma, while Ber-EP4 is more widely expressed in carcinomas with glandular or some other differentiations. The usefulness of these markers in the differential diagnosis of adenocarcinoma cells and mesothelial cells was confirmed in this study, showing strong expressions of these markers in adenocarcinoma cells and complete absence of expressions in mesothelial cells. Given their high specificity and sensitivity, Ber-EP4 was adopted as a marker for adenocarcinoma in the rapid fluorescence ICC procedure in our study. Contrary to those for adenocarcinoma, there have been few positive markers for mesothelial cells until recently. HBME-1, thrombomodulin and mesothelin, which have been used for a relatively long time, show a high sensitivity to mesothelial cells, but in a sizable percentage of adenocarcinoma cases they are also seen in the expression of these markers $[14,15]$. Therefore, use of HBME-1, thrombomodulin and mesothelin as specific markers for mesothelial cells has been limited to special occasions. Calretinin, cytokeratin $5 / 6$, D2-40 and WT1 are recently developed markers reported to be more specific than those mentioned above $[10,16$, 17]. Desmin is originally a marker for muscle cells and also reported to be expressed in reactive mesothelial cells but not in mesothelioma cells, thus being used for the differentiation of the latter two cells [3]. In the present study, mesothelial cells showed relatively strong positivities for these markers. By preserving peritoneal cell specimens in LBC solution, ICC can obtain almost all of the possible antibodies necessary for diagnosis. We therefore achieved a high degree of diagnostic accuracy compared to a cytomorphologic evaluation with only conventional Papanicolaou, PAS, or Giemsa stain. However, it is costly to perform many kinds of ICC on all cases. To be more cost- effective, one must carefully observe the conventional Papanicolaou, PAS, or Giemsa stain.

To improve diagnostic accuracy, ICC or fluorescence in situ hybridization (FISH) for intraoperative cancer diagnosis has been performed in various organs. However, its application to effusion cytology is not common, especially in fluorescence ICC [18-21]. In this study, we conducted the rapid procedure for fluorescence ICC using Ber-EP4 that can be performed within 20 min using the liquid-phase method. Although the mechanism by which the antigen-antibody reaction time is shortened by the liquid-phase method has not yet been fully clarified, we found out that it yielded the same results as both standard ICC and standard fluorescence ICC. The combined use of our rapid procedure for the fluorescence ICC technique with other staining methods proved useful for improving intraoperative cytological diagnosis. This procedure can be performed much more easily with LBC specimens. When a conventional Papanicolaou-stained slide is examined and immunostaining is indicated, decoloration of the Papanicolaou slide is usually unavoidable unless additional slides are incidentally preserved in ethanol. The LBC system is superior in that one can preserve cells for 1 or 2 months in an optimal state without losing antigenicity in the cells and even for more than 1 year in a fairly adequate state. Thus, cells preserved in LBC solution can be used not only for ICC but also for FISH or other molecular techniques at the same time as or after Papanicolaou, Giemsa or some other conventional stains.

In conclusion, immunocytochemical examination with the LBC method is a powerful ancillary technique for the differentiation of adenocarcinoma cells from mesothelial cells in body fluid effusion cytology. The rapid new procedure for fluorescence ICC can be used as an ancillary technique for detecting adenocarcinoma cells in the intraoperative cytological examination of peritoneal or pleural washing fluid with a high degree of diagnostic accuracy. The LBC method is an excellent cell preparation technique that can be applied to various diagnostic and research techniques.

\section{Acknowledgments}

The author is grateful to Dr. Takehito Watanabe, Watanabe Clinic, and Dr. Masafumi Ito, Japanese Red Cross Nagoya Daiichi Hospital, for their enlightening advice. 


\section{References}

1 Morgan RL, De Young BR, McGaughy VR, Niemann TH: MOC-31 aids in the differentiation between adenocarcinoma and reactive mesothelial cells. Cancer 1999;87:390-394.

$>2$ Politi E, Kandaraki C, Apostolopoulou C, Kyritsi $\mathrm{T}$, Koutselini $\mathrm{H}$ : Immunocytochemical panel for distinguishing between carcinoma and reactive mesothelial cells in body cavity fluids. Diagn Cytopathol 2005;32:151-155.

-3 Attanoos RL, Griffin A, Gibbs AR: The use of immunohistochemistry in distinguishing reactive from neoplastic mesothelium. A novel use for desmin and comparative evaluation with epithelial membrane antigen, p53, platelet-derived growth factor-receptor, P-glycoprotein and Bcl-2. Histopathology 2003;43: 231-238.

4 Japanese Gastric Cancer Association: Japanese Classification of Gastric Carcinoma, ed 14. Tokyo, Kanehara, 2010.

$>5$ Grefte JM, de Wilde PC, Salet-van de Pol MR, et al: Improved identification of malignant cells in serous effusions using a small, robust panel of antibodies on paraffin-embedded cell suspensions. Acta Cytol 2008;52:35-44.

6 Bernstein SJ, Sanchez-Ramos L, Ndubisi B: Liquid-based cervical cytologic smear study and conventional Papanicolaou smears: a metaanalysis of prospective studies comparing cytologic diagnosis and sample adequacy. Am J Obstet Gynecol 2001;185:308-317.

$>7$ Nasuti JF, Tam D, Gupta PK: Diagnostic value of liquid-based (ThinPrep) preparations in nongynecologic cases. Diagn Cytopathol 2001;24:137-141.
8 Sakakibara E, Kimachi S, Hashimoto K, et al: An aspiration material preparation system: application of a new liquid-based cytology technique for fine-needle aspiration of the breast. Acta Cytol 2011;55:92-99.

$\checkmark 9$ Delahaye M, van der Ham F, van der Kwast TH: Complementary value of five carcinoma markers for the diagnosis of malignant mesothelioma, adenocarcinoma metastasis, and reactive mesothelium in serous effusions. Diagn Cytopathol 1997;17:115-120.

10 Ordóñez NG: The immunohistochemical diagnosis of mesothelioma: a comparative study of epithelioid mesothelioma and lung adenocarcinoma. Am J Surg Pathol 2003;27:10311051.

11 Saad RS, Cho P, Liu YL, Silverman JF: The value of epithelial membrane antigen expression in separating benign mesothelial proliferation from malignant mesothelioma: a comparative study. Diagn Cytopathol 2005; 32:156-159.

12 Ordóñez NG: Value of the MOC-31 monoclonal antibody in differentiating epithelial pleural mesothelioma from lung adenocarcinoma. Hum Pathol 1998;29:166-169.

13 González-Lois C, Ballestín C, Sotelo MT, et al: Combined use of novel epithelial (MOC-31) and mesothelial (HBME-1) immunohistochemical markers for optimal first line diagnostic distinction between mesothelioma and metastatic carcinoma in pleura. Histopathology $2001 ; 38: 528-534$.
14 Kennedy AD, King G, Kerr KM: HBME-1 and antithrombomodulin in the differential diagnosis of malignant mesothelioma of pleura. J Clin Pathol 1997;50:859-862.

15 Ordóñez NG: Application of mesothelin immunostaining in tumor diagnosis. Am J Surg Pathol 2003;27:1418-1428.

16 Fetsch PA, Simsir A, Abati A: Comparison of antibodies to HBME-1 and calretinin for the detection of mesothelial cells in effusion cytology. Diagn Cytopathol 2001;25:158-161.

17 Ordóñez NG: D2-40 and podoplanin are highly specific and sensitive immunohistochemical markers of epithelioid malignant mesothelioma. Hum Pathol 2005;36:372380 .

18 Koide K, Sakakura C, Hagiwara A, et al: An improved rapid procedure for fluorescence in situ hybridization that is applicable to intraoperative cancer cytodiagnosis. Cancer Lett 2000;158:165-169.

19 Mönig SP, Luebke T, Soheili A, et al: Rapid immunohistochemical detection of tumor cells in gastric carcinoma. Oncol Rep 2006;16: 1143-1147.

20 Furuhata A, Sueyoshi N, Kurihara H, et al: Rapid multiple immunocytochemical staining method using microwave irradiation for intraoperative cytology. Acta Cytol 2010;54: 283-290.

21 Denda T, Kamoshida S, Kawamura J, et al: Rapid immunocytochemistry with simple heat-induced antigen retrieval technique for improvement in the quality of cytological diagnosis. J Histochem Cytochem 2013;61:920930 